\title{
Exposure to high concentrations of nitrosamines and cancer mortality among a cohort of rubber workers
}

Kurt Straif, Stephan K Weiland, Martina Bungers, Dagmar Holthenrich, Dirk Taeger, Sun Yi, Ulrich Keil

\begin{abstract}
Objectives-To examine if the occurrence of different cancers was increased among rubber workers, as the highest known exposures of humans to nitrosamines have occurred in the rubber industry.

Methods-A cohort of 8933 rubber workers (hired after 1 January 1950, still active or retired on 1 January 1981 and employed for at least 1 year in one of five study factories) was followed up for mortality from 1 January 1981 to 31 December 1991 . Work histories were reconstructed with routinely documented cost centre codes, which allowed identification by employment in specific work areas. For each cost centre code time and factory specific, semi-quantitative exposures to nitrosamines (three levels: low, medium, high) and other compounds were estimated by industrial hygienists. Rate ratios for medium $\left(\mathbf{R R}_{\mathrm{m}}\right)$ and high $\left(\mathbf{R R}_{\mathrm{h}}\right)$ exposures and 95\% confidence intervals (95\% CIs) were calculated with Cox's proportional hazards models with the low exposure as reference.
\end{abstract}

Results-Exposure to nitrosamines was significantly associated with an increased mortality from cancers of the oesophagus (13 deaths: $R_{\mathrm{m}} 1.7,95 \%$ CI 0.3 to $10.3 ; R_{\mathrm{h}}$ $7.3,95 \%$ CI 1.9 to 27.8 ) and of the oral cavity and pharynx (17 deaths: $R_{\mathrm{m}} \mathbf{0 . 8}, 95 \%$ CI 0.2 to $4.1 ; R_{h} 3.9,95 \%$ CI 1.4 to 11.1$)$. A non-significant trend of increasing mortality with exposure to higher concentrations of nitrosamines was found for mortality from cancer of the prostate (26 deaths: $R_{\mathrm{m}} 1.4,95 \% \mathrm{CI} 0.5$ to $3.8 ; R_{\mathrm{h}} 2.2$, 95\% CI 0.9 to 5.6 ), and the brain (six deaths: $\mathbf{R R}_{\mathrm{m}} 3.9,95 \%$ CI 0.3 to 42.6 ; $\mathbf{R R}_{\mathrm{h}}$ $6.0,95 \%$ CI 0.6 to 57.6 ). No association was found between exposure to nitrosamines and cancer of the stomach $\left(R_{\mathrm{m}} \mathbf{0 . 8}, \mathbf{9 5 \%}\right.$ CI 0.4 to $1.8 ; R_{h} 1.2,95 \%$ CI 0.5 to 2.5 ) or lung $\left(\mathbf{R R}_{\mathrm{m}} 1.0,95 \%\right.$ CI 0.6 to $1.5 ; \mathbf{R R}_{\mathrm{h}} 1.0$, 95\% CI 0.7 to 1.6$)$.

Conclusions-Exposure to high concentrations of nitrosamines is associated with increased mortality from cancers of the oesophagus, oral cavity, and pharynx, but not with increased mortality from cancers of the stomach or lung.

(Occup Environ Med 2000;57:180-187)

Keywords: nitrosamines; cancer mortality; rubber industry
In 1956 Magee and Barnes ${ }^{1}$ showed the carcinogenic potential of nitrosodimethylamine (NDMA) in rats. Since then about $90 \%$ of the 300 tested nitrosamines have shown potent carcinogenic effects in experimental studies ${ }^{2}$ in at least 39 different species ${ }^{3}$ and many different organs. ${ }^{4}$ Predominant sites of tumour induction in animals include oral cavity, oesophagus, stomach, urinary bladder, and brain. ${ }^{25}$ Doseresponse studies in animals have indicated "no effect levels" for specific nitrosamines-such as NDMA and nitrosodiethylamine (NDEA) which correspond to dietary concentrations as low as 1 ppm. ${ }^{67}$ No animal species has been found to be resistant and experimental data provide little evidence that humans are resistant to the carcinogenic effect of nitrosamines. ${ }^{5}$

Nitrosamines are ubiquitous in the human environment and have been detected in food items, including cured meat, bacon, fish, and beer, in cosmetics, drugs, and in the front passenger areas of new cars. ${ }^{8-12}$ High nonoccupational exposures of humans result from the consumption of smokeless or burned tobacco. ${ }^{5} 101113$

Evidence directly linking exposure to nitrosamines and cancer in humans, however, has been difficult to establish because exposures in the human environment often occurred to low concentrations of nitrosamines and complex mixtures. Therefore only two specific $\mathrm{N}$-nitroso compounds, NDMA and NDEA, have been classified by the International Agency for Research on Cancer (IARC) as "probably carcinogenic to humans". ${ }^{14}$

The highest concentrations of nitrosamines in the human environment have been measured in the rubber industry. ${ }^{15-17}$ However, exposure conditions in this industry are complex and despite a long history of epidemiological investigations of carcinogenic risks in this industry ${ }^{19}$ no previous study has specifically investigated exposure to nitrosamines.

We have conducted a large historic cohort study in the German rubber industry. ${ }^{20-22}$ This is the first report on cancer risks associated with occupational exposure in the rubber industry focusing particularly on nitrosamines.

\section{Methods}

The cohort definition and follow up have previously been described ${ }^{20}$ and are only briefly summarised here. The originally defined cohort included all male German blue collar workers who were employed for at least 1 year 
in any one of five study factories and who were alive and actively employed or retired on 1 January $1981 \quad(n=11663)$. This originally defined cohort was then restricted to all workers who were hired on or after 1 January 1950 $(n=8933)$ to focus on potential risks of working conditions in the more recent rubber industry and to reduce the potential for a healthy worker survivor effect. Furthermore, due to uncertainties about changes of production processes and factory structures during and after the second world war, it was necessary to limit exposure assessment to the time from 1950 onwards. Follow up of individual cohort members started on 1 January 1981 but not before completion of 1 year of employment, and ended at death, or the end of the follow up period, 31 December 1991. Follow up of individual cohort members ended also at the age of 85 years, because the reported causes of death on the death certificate of very old people may be less valid and the specific causes less likely to be related to occupation. Health insurance data and personnel files of the participating factories as well as German population registries were used to determine the vital status of cohort members at the end of the observation period. In the case of deceased cohort members, death certificates were requested from community health departments. The underlying causes of death as reported on death certificates were coded by professional nosologists from the State Institute of Statistics of North-Rhine-Westphalia according to the ninth revision of the International classification of diseases, injuries, and deaths (ICD-9). ${ }^{23}$

Individual work histories within the rubber companies were reconstructed with routinely documented cost centre codes (Kostenstellen). ${ }^{21}$ These were originally generated for accounting purposes, but allow identification of employment in specific work areas in the respective periods. As environmental monitoring of nitrosamines was not performed before 1979, retrospective semiquantitative estimates of exposure were necessary. Together with industrial hygienists from the rubber factories involved and external experts a scheme for categorising exposure was developed (table 1). ${ }^{162425}$

The categorisation scheme and the exposure assessment for nitrosamines was based on evidence from a hazard survey in the early 1980 s that included several of the factories involved in this epidemiological study. The highest nitrosamine concentrations were detected in curing and vulcanisation: $1060 \mu \mathrm{g} / \mathrm{m}^{3}$ of NDMA and $4700 \mu \mathrm{g} / \mathrm{m}^{3}$ of $\mathrm{N}$-nitrosomorpholin. ${ }^{16}$ Comprehensive nitrosamine measurements in all factories were performed soon after that survey. Information on changes of production processes and introduction of improved technical safety equipment within different tasks was used to estimate exposure back through time.

Most of the nitrosamines detected in the air of rubber factories are formed during vulcanisation. N-nitrosodiphenylamine (NDPhA), which was used as a retarder until early $1980,{ }^{26}$ has shown only limited carcinogenic effects in animals. ${ }^{27}$ However, it was found to serve as a potent transnitrosating agent ${ }^{28}$ thereby increasing exposure to total nitrosamines by an order of magnitude. ${ }^{16}$ Also, salt bath curing resulted in some of the highest concentrations of nitrosamines, ${ }^{61629}$ except when peroxide accelerators were used instead of amine derivatives. ${ }^{16}$ Medium concentrations of nitrosamines were detected in vulcanisation and subsequent production steps in production lines where neither NDPhA nor salt bath curing with peroxides was used. In production processes before vulcanisation-such as raw material handling, weighing and mixing, extruding and calendering, and component building - in general, only relatively low nitrosamine concentrations were detected. We assessed exposure to total nitrosamines because animal studies indicated linear additive carcinogenicity for exposure to low concentrations of different nitrosamines, ${ }^{30}$ and because assessment of exposure to specific nitrosamines would not have been possible. On the basis of our categorisation scheme, industrial hygien-

Table 1 Results of hazards survey * and categories for assessment of exposure to nitrosaminest

\begin{tabular}{|c|c|c|c|}
\hline Work area & Nitrosamine $\neq$ & $\begin{array}{l}\text { Concentration } \\
\text { in air }\left(\mu \mathrm{g} / \mathrm{m}^{3}\right)^{\star}\end{array}$ & $\begin{array}{l}\text { Exposure } \\
\text { categoryt }\end{array}$ \\
\hline $\begin{array}{l}\text { Salt bath curing (except for salt bath curing with only peroxide } \\
\text { accelerators) }\end{array}$ & $\begin{array}{l}\text { NDMA } \\
\text { NMOR }\end{array}$ & $1-130$ & High \\
\hline \multicolumn{4}{|l|}{ Vulcanisation and subsequent production stages with use of NDPhA $\ddagger$} \\
\hline Tube vulcanisation & NDMA & $15-140$ & \\
\hline \multirow{2}{*}{ Injection moulding } & NDMA & $40-90$ & \\
\hline & NMOR & $120-380$ & \\
\hline Tube and tyre warehouse & NDMA & $4-20$ & \\
\hline \multicolumn{3}{|l|}{ Same production stages (as above) without use of NDPhA } & Medium \\
\hline Tube vulcanisation & NDMA & $1-4.5$ & \\
\hline Tube and tyre warehouse & NDMA & $1-4.5$ & \\
\hline \multicolumn{4}{|l|}{ Other hot processes starting with vulcanisation: } \\
\hline \multirow[t]{2}{*}{ Tyre vulcanisation } & NDMA & $0.1-2$ & \\
\hline & NMOR & $0.1-17$ & \\
\hline Injection moulding: soles of shoe & NDMA & $0.2-3.5$ & \\
\hline \multicolumn{3}{|l|}{ Work areas before vulcanisation: } & Low \\
\hline \multirow[t]{2}{*}{ Raw material handling, weighing, and mixing } & NDMA & $0.1-0.9$ & \\
\hline & NMOR & $0.1-2$ & \\
\hline \multirow[t]{2}{*}{ Milling, extruding, calendering } & NDMA & $0.1-2$ & \\
\hline & NMOR & $0.1-9$ & \\
\hline \multirow[t]{2}{*}{ Assembly and building } & NDMA & $0.1-1$ & \\
\hline & NMOR & $0.5-3$ & \\
\hline
\end{tabular}

*Adapted from tables I-V. ${ }^{16}$

†According to workshop with B Spiegelhalder, H Kromhout, R Vermeulen, K Norpoth, members of the Berufsgenossenschaft and industrial hygienists and occupational physicians of the rubber factories involved.

$\ddagger \mathrm{NDPhA}=\mathrm{N}$-nitrosodiphenylamine; NDMA $=\mathrm{N}$-nitrosodimethylamine; $\mathrm{NMOR}=\mathrm{N}$-nitrosomorpholine. 
ists of the factories estimated calendar time and factory specific exposure-that is, airborne concentrations, for each cost centre code, independently of individual cohort members. This information was then linked on the basis of cost centre codes with the occupational histories of cohort members within the rubber industry. The retrospective exposure assessment was based on judgements of the industrial hygienists. The following cut off points served to classify exposure to nitrosamines: for the high exposure category nitrosamine concentrations were assumed to be $>15 \mu \mathrm{g} / \mathrm{m}^{3}$. The current technical limit value of $2.5 \mu \mathrm{g} / \mathrm{m}^{3}$ for nitrosamine exposure for specific operations in the German rubber industry ${ }^{31}$ served as upper boundary for the low exposure category.

DATA ANALYSIS

For exposure specific analyses cohort members were classified into initially determined exposure categories. Within exposure category 1, high exposure for each variable included workers who had been employed for at least 1 year in cost centre codes with high exposures, and low exposure included workers who had been employed for $<1$ year at medium or high exposures. Otherwise workers were included in the medium exposure category. Within exposure category 2 (the more extreme category) the cut off points were 10 years for high exposure and 0.5 years for low, respectively. Exposure was treated as time dependent variable - that is, risk sets were formed whenever a death from a cancer of interest occurred in the cohort-and an exposure category was assigned to the index case and the corresponding risk set according to the current exposure status. Exposure was further lagged by 10 years to account for latency. Lagging was performed so that a worker's current person-years at risk was assigned to the exposure concentration reached 10 years earlier. $^{32}$

Hazard rate ratios (RRs) and $95 \%$ confidence intervals (95\% CIs) for exposure to nitrosamines were calculated with low exposure as the reference. The SAS procedure PROC PHREG. 6.12 was used to calculate time dependent and age (time marker) adjusted RRs. Trend tests were performed with exposure scores (low $=0$, medium $=1$, high $=2$ ) as covariates in the proportional hazards model. All analyses were restricted to cohort members with complete time dependent exposure information in the respective model. ${ }^{33}$

\section{Results}

The distribution of cohort members by age group and employment is given in table 2 . At the beginning of follow up, overall 6875 cohort members were actively employed in the rubber industry and 2058 were retired. At the end of follow up vital status was unknown for 31 of 8933 cohort members $(0.3 \%)$ and cause of death was unknown for 42 of 1521 deceased cohort members $(2.8 \%)$. Complete occupational histories on the basis of cost centre codes as well as calendar time and factory specific exposure assessment for these cost centre codes was available for $94.8 \%$ of the cohort
Table 2 Distribution of cohort members $(n=8933)$ by age and employment (retired $n=2058$, active $n=6875$ ) at beginning of follow up

\begin{tabular}{|c|c|c|c|c|c|c|}
\hline \multirow[b]{2}{*}{ Age } & \multicolumn{2}{|l|}{ Active } & \multicolumn{2}{|c|}{ Retired } & \multicolumn{2}{|c|}{ Overall } \\
\hline & $n$ & $\%$ & $n$ & $\%$ & $n$ & $\%$ \\
\hline$\leqslant 39$ & 1772 & 25.8 & 6 & 0.3 & 1778 & 19.9 \\
\hline $40-49$ & 2702 & 39.3 & 44 & 2.1 & 2746 & 30.7 \\
\hline $50-59$ & 2349 & 34.2 & 322 & 15.6 & 2671 & 29.9 \\
\hline$\geqslant 60$ & 52 & 0.8 & 1686 & 81.9 & 1738 & 19.4 \\
\hline Overall & 6875 & 100 & 2058 & 100 & 8933 & 100 \\
\hline
\end{tabular}

Table 3 Distribution of cohort members $(n=8933)$ by categories of exposure to nitrosamines and date of hire

\begin{tabular}{|c|c|c|c|c|}
\hline \multirow{2}{*}{$\begin{array}{l}\text { Date of start } \\
\text { of employment }\end{array}$} & \multicolumn{2}{|c|}{ Exposure category 1} & \multicolumn{2}{|c|}{ Exposure category 2} \\
\hline & $n$ & $\%$ & $n$ & $\%$ \\
\hline \multicolumn{5}{|l|}{ 1950-9: } \\
\hline High & 1363 & 30.6 & 945 & 21.2 \\
\hline Medium & 1176 & 26.4 & 1645 & 36.9 \\
\hline Low & 1683 & 37.8 & 1629 & 36.6 \\
\hline Missing & 231 & 5.2 & 234 & 5.3 \\
\hline \multicolumn{5}{|l|}{ 1960-9: } \\
\hline High & 899 & 28.4 & 586 & 18.5 \\
\hline Medium & 787 & 24.8 & 1145 & 36.1 \\
\hline Low & 1359 & 42.9 & 1312 & 41.4 \\
\hline Missing & 123 & 3.9 & 125 & 3.9 \\
\hline \multicolumn{5}{|l|}{ 1970-80: } \\
\hline High & 189 & 14.4 & 36 & 2.7 \\
\hline Medium & 274 & 20.9 & 477 & 36.4 \\
\hline Low & 738 & 56.3 & 714 & 54.4 \\
\hline Missing & 111 & 8.5 & 85 & 6.5 \\
\hline \multicolumn{5}{|l|}{ Overall: } \\
\hline High & 2451 & 27.4 & 1567 & 17.5 \\
\hline Medium & 2237 & 25.0 & 3267 & 36.6 \\
\hline Low & 3780 & 42.3 & 3655 & 40.9 \\
\hline Missing & 465 & 5.2 & 444 & 5.0 \\
\hline
\end{tabular}

members (table 3). Distribution of workers by exposure to nitrosamines by date of hire and by the two exposure categories is shown in table 3. With exposure category 1 , about $25 \%$ of the cohort members were exposed to high and $25 \%$ to medium nitrosamine concentrations. With exposure category 2, about $20 \%$ of the cohort members were assigned to high and $40 \%$ to medium nitrosamine concentrations. With both exposure categories there was a trend of decreasing nitrosamine exposure by date of hire.

Mortality from all causes and all cancers increased slightly with exposure to higher concentrations of nitrosamines (table 4). Tests for trend and associations with exposure to high concentrations of nitrosamines were significant for cancer of the oesophagus, and cancers of the lip, oral cavity, and pharynx. The comparison of results between exposure categories 1 and 2 show that the observed risks were higher when exposure category 2 was used. The results for the subgroups of cancer of the oral cavity versus cancer of the pharynx show slightly higher risks for cancer of the pharynx. However, overall the effect estimates for the two subgroups did not differ substantially and any difference may be due to chance. One death from pharyngeal cancer was excluded from analyses, because we had no information on cost centre code and potential exposures for the first 14 months of employment in the rubber industry in the early 1960s. According to the exposure assessment, he was not exposed to nitrosamines during his subsequent employment in the rubber industry. 
Table 4 Exposure to nitrosamines and cancer mortality among male workers $(n=8933)$ in the rubber industry

\begin{tabular}{|c|c|c|c|c|c|c|c|c|c|c|c|c|}
\hline \multirow[b]{3}{*}{ Cancer } & \multirow[b]{3}{*}{$I C D-9$} & \multirow[b]{3}{*}{ Deaths } & \multicolumn{4}{|c|}{ Exposure category $1^{*}$} & \multirow{3}{*}{$\begin{array}{l}\text { Wald } \\
\chi^{2} \text { for } \\
\text { trend } \neq\end{array}$} & \multicolumn{4}{|c|}{ Exposure category $2 \dagger$} & \multirow{3}{*}{$\begin{array}{l}\text { Wald } \chi^{2} \\
\text { for } \\
\text { trend } \neq\end{array}$} \\
\hline & & & \multicolumn{2}{|c|}{ Medium } & \multicolumn{2}{|c|}{ High } & & \multicolumn{2}{|c|}{ Medium } & \multicolumn{2}{|c|}{ High } & \\
\hline & & & $R R$ & $95 \% C I$ & $R R$ & $95 \% C I$ & & $R R$ & $95 \% C I$ & $R R$ & $95 \% C I$ & \\
\hline All causes & 000-999 & 1429 & 1.2 & 1.1 to 1.4 & 1.3 & 1.1 to 1.4 & 4.73 & 1.2 & 1.0 to 1.5 & 1.4 & 1.0 to 1.8 & 13.92 \\
\hline All cancers ${ }^{\star \star}$ & $140-208$ & 444 & 1.2 & 0.9 to 1.5 & 1.3 & 1.1 to 1.7 & 5.67 & 1.2 & 1.0 to 1.5 & 1.4 & 1.0 to 1.8 & 5.25 \\
\hline \multicolumn{13}{|l|}{ Cancer: } \\
\hline $\begin{array}{l}\text { Lip, oral cavity, } \\
\text { pharynx } \dagger \dagger\end{array}$ & $140-149$ & 17 & 0.8 & 0.2 to 4.1 & 3.9 & 1.4 to 11.1 & 6.18 & 3.6 & 1.1 to 11.7 & 5.1 & 1.2 to 20.6 & 6.24 \\
\hline Oral cavity & $141,143-145$ & 7 & 0.9 & 0.1 to 8.6 & 2.9 & 0.6 to 14.4 & 1.38 & 3.4 & 0.6 to 18.8 & 2.9 & 0.3 to 33.3 & 1,46 \\
\hline Pharynxt† & $146-149$ & 9 & 0.8 & 0.1 to 7.9 & 4.1 & 1.0 to 17.2 & 3.54 & 3.8 & 0.7 to 19.9 & 4.7 & 0.6 to 33.5 & 2.99 \\
\hline Oesophagus & 150 & 13 & 1.7 & 0.3 to 10.3 & 7.3 & 1.9 to 27.8 & 9.45 & 2.7 & 0.7 to 11.5 & 9.1 & 2.1 to 38.8 & 9.53 \\
\hline Stomach $\mathbb{S}$ & 151 & 44 & 0.8 & 0.4 to 1.8 & 1.2 & 0.5 to 2.5 & 0.20 & 0.9 & 0.5 to 1.8 & 1.2 & 0.5 to 3.2 & 0.06 \\
\hline Colon & 153 & 21 & 0.4 & 0.1 to 1.7 & 1.5 & 0.6 to 3.8 & 0.25 & 0.6 & 0.2 to 1.8 & 1.5 & 0.5 to 4.7 & 0.03 \\
\hline Rectum & 154 & 19 & 0.8 & 0.2 to 2.3 & 0.6 & 0.2 to 2.3 & 0.61 & 0.8 & 0.3 to 2.2 & 0.8 & 0.2 to 3.9 & 0.15 \\
\hline $\begin{array}{l}\text { Liver, gall } \\
\text { bladder }\end{array}$ & $155-156$ & 9 & 0.9 & 0.2 to 4.5 & 1.1 & 0.2 to 5.7 & 0.00 & 0.9 & 0.2 to 3.8 & 1.0 & 0.1 to 8.3 & 0.01 \\
\hline Pancreas & 157 & 15 & 0.7 & 0.2 to 2.7 & 0.5 & 0.1 to 2.4 & 0.83 & 0.9 & 0.3 to 2.6 & 0.5 & 0.1 to 4.4 & 0.33 \\
\hline Larynx & 161 & 8 & 0.4 & 0.0 to 3.1 & 0.4 & 0.0 to 3.0 & 1.30 & 0.5 & 0.1 to 2.3 & 0.0 & - & 1.98 \\
\hline Lung $₫$ t夫 & 162 & 147 & 1.0 & 0.6 to 1.5 & 1.0 & 0.7 to 1.6 & 0.02 & 1.0 & 0.7 to 1.5 & 1.1 & 0.6 to 1.8 & 0.14 \\
\hline Prostate & 185 & 26 & 1.4 & 0.5 to 3.8 & 2.2 & 0.9 to 5.6 & 2.42 & 1.6 & 0.7 to 3.7 & 2.1 & 0.7 to 6.2 & 1.89 \\
\hline Bladder & 188 & 21 & 1.1 & 0.4 to 3.3 & 1.5 & 0.5 to 4.2 & 0.53 & 1.2 & 0.5 to 3.0 & 1.3 & 0.4 to 5.0 & 0.20 \\
\hline Kidney & 189 & 10 & 1.2 & 0.3 to 4.7 & 0.4 & 0.0 to 3.5 & 0.46 & 1.0 & 0.3 to 3.6 & 0.0 & - & 0.71 \\
\hline Brain, CNS & $191-192$ & 6 & 3.9 & 0.3 to 42.6 & 6.0 & 0.6 to 57.6 & 2.63 & 5.1 & 0.6 to 45.6 & 3.5 & 0.2 to 56.2 & 1.26 \\
\hline Lymphoma & $200-203$ & 14 & 2.0 & 0.7 to 6.2 & 0.3 & 0.0 to 2.8 & 0.24 & 2.0 & 0.7 to 5.9 & 0.0 & - & 0.04 \\
\hline Leukaemiat† & $204-208$ & 20 & 1.3 & 0.5 to 3.6 & 1.2 & 0.4 to 3.5 & 0.12 & 1.3 & 0.5 to 3.4 & 0.8 & 0.2 to 3.5 & 0.0 \\
\hline
\end{tabular}

*Category 1 : high $=\geqslant 1$ year in high exposure; low $=<1$ year in medium and high exposure (combined).

†Category 2 : high $=\geqslant 10$ years in high exposure; low $=<0.5$ year in medium and high exposure (combined).

†Values $>3.84$ correspond to $\mathrm{p}$ values (two tailed) $<0.05$, values $>2.72$ correspond to $\mathrm{p}$ values $<0.1$.

§HRR adjusted for exposure to asbestos, talc, and carbon black.

ๆ46 Cases with incomplete exposure data excluded from analyses.

$\star \star 11$ Cases with incomplete exposure data excluded from analyses.

t†1 Case with incomplete exposure data excluded from analyses.

†7 Cases with incomplete exposure data excluded from analyses.

9 92 Cases with incomplete exposure data excluded from analyses.

We also found an exposure-response relation, although not significant, and similar for both exposure categories between exposure to nitrosamines and mortality from prostate cancer. For two cases of prostate cancer exposure information was missing for the first work period of 7 and 9 years in the late 1950s. Both workers were exposed to low concentrations of nitrosamines in subsequent jobs in the rubber industry. For brain cancer a non-significant exposure-response relation was found, which was more pronounced for exposure category 1 . However, the findings for brain cancer were based on only six cases.

Exposure to nitrosamines was not associated with mortality from lung and stomach cancer and these effect estimates did not change substantially after adjustment for exposure to asbestos, talc, and carbon black. For seven cases $(4.5 \%)$ of lung cancer no exposure information was available for their first employment period, which was mostly in the late 1950s and early 1960 s and lasted $2-21$ years. Subsequently these workers were not exposed to nitrosamines; however, two of the seven were exposed to asbestos, talc, and carbon black.

\section{Discussion}

The highest documented exposures of humans to nitrosamines have occurred in the rubber industry. On the basis of our earlier analyses by work area among this cohort of rubber workers $^{22}$ we had speculated that nitrosamines may have played a part in the excess risk of cancers of the pharynx, oesophagus, and urinary bladder. This is the first study to investigate occupational exposure to nitrosamines and cancer risks among workers in the rubber industry.
This cohort was restricted to workers who were alive and active or retired on 1 January 1981. This may have led to a cohort of survivors and may thus have resulted in underestimation of the true risk associated with exposure to nitrosamines. By contrast, if more heavily exposed workers or those ill with cancer stayed, and less exposed or mostly the healthy workers moved on, this cohort definition may have resulted in overestimation of the true risk. However, the restriction of the cohort to workers who were employed after 1 January 1950 resulted in a more homogenous cohort and reduced the potential for a healthy worker survivor effect. Furthermore, the small excess risks found for all cause and all cancer mortality may, at least in part, be explained by excess mortality from diseases associated with exposure to nitrosamines. Therefore, these results argue against a strong healthy worker survivor effect as well as against a substantial overestimation of risks.

The assessment of exposure to nitrosamines was carried out by industrial hygienists who were familiar with the factories. This assessment was based on retrospective estimates of exposure for all cost centre codes according to the categorisation scheme, independently of individual workers. Nevertheless, it is likely that some misclassification of exposure occurred. Outcomes of the study were assessed on the basis of death certificates which were coded by professional nosologists. Therefore the potential misclassification would be an independent and non-differential misclassification process of exposure and the observed effect estimates would be biased toward the null value. ${ }^{34}{ }^{35}$ Due to random variation, the empirical misclassification then probably re- 
sults in underestimation of the association. ${ }^{36} 37$ Therefore, with positive findings, preoccupation with non-differential misclassification is rarely warranted. ${ }^{38}$ However, as we investigated the association between nitrosamine exposure and several cancer sites we cannot be sure that the associations found were not due to chance.

Our results show significant excess risks of lip, oral, and pharyngeal cancers among workers who were exposed to high concentrations of nitrosamines. Increased risks of mortality from oral and pharyngeal cancer among rubber workers also have been reported from occupational surveillance data in Great Britain, ${ }^{39}$ and from cohort ${ }^{40-43}$ and case-control studies ${ }^{44}$; only two cohort studies found no increased risk. ${ }^{45} 46$ However, none of these studies provided risk estimates for exposure to nitrosamines.

In non-occupational studies, frequent consumption of foods containing nitrosamines, especially NDMA, has been related to an increased risk of oral cancer in a case-control study. ${ }^{47}$ Furthermore, several reviews concluded that exposure to high concentrations of tobacco specific nitrosamines among snuff dippers $^{48} 49$ is associated with oral cancer ${ }^{49-51}$ and an increased risk of nasopharyngeal carcinoma has been related to the consumption of Cantonese style salted fish, ${ }^{52}$ where high concentrations of NDMA have been identified as major carcinogens. ${ }^{953}$

In experimental animal studies induction of oral and pharyngeal cancer has been found by administration of non-tobacco specific nitrosamines. ${ }^{14}$ Furthermore, it has been shown in non-human primates that systemic administration of low doses of NDMA may result in DNA adducts in the oral mucosa. ${ }^{54}$

The observed exposure-response relation and the strong association between high exposure to nitrosamines and mortality from oesophageal cancer support a causal role of nitrosamine exposure and oesophageal cancer. Significant excess risks of oesophageal cancer have also been found in the British rubber industry ${ }^{42} 43$ and among vulcanisation workers potentially exposed to high concentrations of nitrosamines. ${ }^{55}$ Other studies among rubber workers, however, provided only limited evidence of an excess mortality from oesophageal cancer. ${ }^{22} 56$

Substantial occupational exposure to nitrosamines, especially NDELA, may also have occurred among workers exposed to synthetic metal working fluids. ${ }^{57-59}$ DNA strand breaks were related to exposure to NDELA among those workers, ${ }^{60}$ and in a large cohort study of workers exposed to metal working fluids, significant excess risks for oesophageal cancer were found among workers exposed to nitrosamines. ${ }^{61}$

Further support for an association between exposure to nitrosamines and oesophageal cancer is derived from studies of dietary intake of nitrosamine contaminated food among populations at high risk of oesophageal cancer in China ${ }^{62}{ }^{63}$ and a population based casecontrol study in the United States. ${ }^{47}$

In several animal species it has been shown that the oesophagus is one of the most common sites for tumour induction by nitrosamines. ${ }^{64} 65$ Systemic application of low doses of NDMA resulted in O6 methylguanine DNA adducts in oesophageal tissue of non-human primates, ${ }^{54}$ and nitrosamine metabolism has been shown to be similar in rat and human oesophagus. ${ }^{66-68}$ Higher concentrations of $\mathrm{O} 6$ methylguanine were extracted from DNA of patients with oesophageal cancer from a high risk area in China compared with those from European patients. ${ }^{6970}$ Furthermore, it has been shown that cytochromes $P-4503 \mathrm{~A} 4$, and $2 \mathrm{E} 1$ are involved in activation of NDMA in human oesophageal tissue, ${ }^{71}$ and that nitrosamines can induce cancer in human oesophageal epithelium. ${ }^{62}$

Environmental causes for prostatic cancer remain largely unknown ${ }^{72}$ and our results of a non-significant, moderate exposure-response relation between exposure to nitrosamines and mortality from prostatic cancer may offer a new hypothesis. The prostate is not a typical target organ of nitrosamine induced cancer in laboratory studies. However, two research groups have established rat models for induction of prostatic cancer by systemic application of specific nitrosamines. ${ }^{73-76}$ Among rubber workers excess risks of prostatic cancer have been reported repeatedly among workers in maintenance and general service. ${ }^{22}{ }^{77-79} \mathrm{In}$ all of these jobs workers may have been exposed to nitrosamines through metal working fluids, and exposure to metal working fluids has been related to prostatic cancer among a cohort of automobile workers. ${ }^{80}$ However, in this study an association was found especially for straight oil metal working fluids, and not for synthetic oil metal working fluids, which had been most heavily contaminated by nitrosamines.

Since the first epidemiological evidence of an increased risk of brain tumours among rubber workers in $1949^{81}$ several cohort, ${ }^{41467882-88}$ and case-control studies ${ }^{89-91}$ have reported excess risks of brain tumours. However, other studies among rubber workers ${ }^{42}{ }_{92-95}$ failed to support these findings. Nitrosamides are considered to be some of the most potent experimental carcinogens to induce brain tumours and therefore a role for nitrosamines, which, unlike nitrosamides, require metabolic activation, ${ }^{64}$ has been hypothesised. ${ }^{96}$ Moreover, in vivo activation of NDMA and formation of DNA adducts in brain tissue of primates has been shown recently. ${ }^{54}$ Our results are the first to describe an association between exposure to high concentrations of nitrosamines and brain cancer.

It is unlikely that these findings are confounded by other known risk factors, such as ionising radiation, serious head injuries, or other occupational exposures. However, the lack of precision of our effect estimates is a serious limitation.

In experimental animal studies tumour induction by nitrosamines has been shown in several additional organs, preferentially stomach, colon, liver, pancreas, and lung. ${ }^{14}{ }^{64}$ However, with the exception of stomach cancer, the epidemiological evidence for these other cancer sites is weak. ${ }^{5}{ }^{97-100}$ Our results do not sup- 
port an association between exposure to nitrosamines and mortality from stomach or lung cancer. We have discussed previously that the increased risk of stomach cancer among rubber workers was mostly found in work areas with relatively low exposure to nitrosamines. ${ }^{22}{ }^{101}$ In a large ecological study there was an association of nitrosoproline excretion with oesophageal cancer, but not with stomach cancer. ${ }^{102}$ Furthermore, it has been shown that compared with oesophageal mucosa the stomach of the rat poorly activates nitrosamines. ${ }^{68}$ An association of lung cancer with dietary intake of nitrosamines was found in a case-control study in Uruguay, ${ }^{103}$ but not with exposure to nitrosamines among workers exposed to metal working fluids. ${ }^{104}$

Asbestos has been discussed as a potential occupational risk factor for oral, pharyngeal, ${ }^{105} 106$ and oesophageal ${ }^{107}$ cancers and exposure to asbestos may have occurred in the rubber industry. However overall evidence is weak, and in our cohort none of the cases of oral, pharyngeal, or oesophageal cancer exposed to high concentrations of nitrosamines had been exposed to high concentrations of asbestos.

Sporadic reports suggested an association between exposure to high concentrations of polycylic aromatic hydrocarbons (PAHs) and cancers of the oesophagus, ${ }^{108} 109$ oral cavity, and pharynx. ${ }^{109110}$ Exposure to PAHs may have occurred in the rubber industry through aromatic oils or carbon black. ${ }^{111}$ However, exposure to PAHs in our cohort members was low compared with other industries, and conventional carcinogenic PAHs are not sufficiently volatile to be released into the air in notable quantities during rubber processing. ${ }^{17}$

Tobacco smoking and alcohol drinking are strong risk factors for upper aero-digestive cancers. ${ }^{12-117}$ Currently, we have no data to assess potential confounding by these individual risk factors in our study. However, our results are based on internal comparisons and we have no indication that the prevalence of smoking or alcohol drinking was related to job assignment or exposure to nitrosamines. Furthermore, other smoking related cancers-for example, lung cancer-alcohol related causes of death-for example, alcohol-associated liver cirrhosis or injury and poisoning (data not shown) - and diseases associated with smoking and alcohol-for example, laryngeal cancerwere inversely associated or not associated with exposure to nitrosamines.

It has been hypothesised that the carcinogenic effect of alcohol may be mediated by increased exposure of internal organs to nitrosamines. ${ }^{54} \mathrm{In}$ animal experiments co-exposure to ethanol reduced blood clearance and increased urinary excretion of NDMA in primates, ${ }^{118}$ increased nitrosamine derived alkylation of oesophageal DNA in rats ${ }^{119}$ and primates, ${ }^{54}$ and increased induction of oesophageal tumours by nitrosamines in rats. ${ }^{120} 121$

\section{Conclusions}

Overall, the pattern of excess cancer mortality associated with exposure to nitrosamines is compatible with data from animal experiments. Our results and other recently published epidemiological studies support an association between exposure to nitrosamines and cancers of the oesophagus, oral cavity, and pharynx. It is unlikely that confounding by smoking and alcohol can explain entirely our findings. Interpretation of the effect estimates found for nitrosamine exposure and brain cancer is hampered by non-significant results on the basis of a small number of deaths. The prostate is not a typical target organ for nitrosamine induced carcinogenicity. However, some animal data support our findings, which may offer a new aetiological hypothesis for prostate cancer. Finally, our results do not support an association between exposure to high concentrations of nitrosamines and mortality from lung or stomach cancer.

We thank the participating companies, especially the industrial hygienists and occupational health physicians. Without their help this study would not have been possible. We are particularly grateful to Bertold Spiegelhalder, Hans Kromhout, Roel Vermeulen, and Klaus Norpoth for their scientific advice on retrospective exposure assessment in the rubber industry. Finally we acknowledge the important contributions to this Finally we acknowledge the important contributions to this study from field workers, programmers, and secretaries. The der Chemischen Industrie, Heidelberg.

1 Magee PN, Barnes JM. The production of malignant primary hepatic tumours in the rat by feeding dimethylnitrosamine. BMF 1956;10:114-22.

2 Preussmann R. Public health significance of environmental N-nitroso compounds. IARC Sci Publ 1983;45:3-17.

3 Bogovski P, Bogovski S. Animal species in which N-nitroso compounds induce cancer. Int $\mathcal{F}$ Cancer 1981;27:471-4.

4 Rounbehler DP, Fajen JM, eds. N-nitroso compounds in the Rounbehler DP, Fajen JM, eds. N-nitroso compounds in the
factory environment. Cincinnati: National Institute for factory environment. Cincinnati: Nation

5 Bartsch H, Montesano R. Relevance of nitrosamines to human cancer. Carcinogenesis 1984;5:1381-93.

6 Reh BD, Fajen JM. Worker exposures to nitrosamines in a rubber vehicle sealing plant. Am Ind Hyg Assoc f 1996;57: $918-23$

7 Crampton RF. Carcinogenic dose-related response to nitrosamines. Oncology 1980;37:251-4.

8 Rounbehler DP, Reisch J, Fine DH. Nitrosamines in new motor-cars. Food Cosmet Toxicol 1980;18:147-51.

9 Mirvish SS. Role of N-nitroso compounds (NOC) and $\mathrm{N}$-nitrosation in etiology of gastric, esophageal, nasopharyngeal and bladder cancer and contribution to cancer of known exposures to NOC Cancer Lett 1995;93:17-48.

of known exposures to NOC. Cancer Lett 1995;93:17-48. Frank CW, Berry CM. N-Nitrosamines. In: Clayton GD,
Clayton FE, eds. Patty's Industrial hygiene and toxicology, Clayton FE, eds. Patty's Industrial hygiene and toxic
3rd. rev. ed. New York: John Wiley, 1981:3117-33.

11 Preussmann R. Occurrence and exposure to N-nitroso compounds and precursors. IARC Sci Publ 1984;57:3-15.

12 Fine DH. Nitrosamines in the general environment and food. In: Magee PN, ed. Nitrosamines and human cancer. Cold Spring Harbor: Cold Spring Harbor Laboratory, 1982:199-209.

13 Eisenbrand G, Köhl W. N-Nitrosoverbindungen. In: Marquardt H, Schäfer SG, eds. Lehrbuch der Toxikologie. Mannheim: BI-Wiss.-Verl, 1994:481-91.

14 International Agency for Research on Cancer. Some $\mathrm{N}$-nitroso compounds. Lyon: IARC, 1978.

15 Fajen JM, Carson GA, Rounbehler DP, et al. $\mathrm{N}$-nitrosamines in the rubber and tire industry. Science 1979;205:1262-4.

16 Spiegelhalder B, Preussmann R. Occupational nitrosamine exposure. 1. Rubber and tyre industry. Carcinogenesis 1983; 4:1147-52.

17 Nutt AR. Toxic hazards of rubber chemicals. London: Elsevier, 1984

18 Case RA, Hosker ME. Tumour of the urinary bladder as an occupational disease in the rubber industry in England and Wales. Br F Prev Soc Med 1954;8:39-50.

19 Case RA, Hosker ME, McDonald DB, et al. Tumours of the urinary bladder in workmen engaged in the manufacture and use of certain dyestuff intermediates in the British chemical industry. Part I. The role of aniline, benzidine, $\alpha$-naphthylamine, and $\beta$-naphthylamine. $B r \mathcal{F}$ Ind $M e d$ 1954;11:75-104.

20 Weiland SK, Mundt KA, Keil U, et al. Cancer mortality among workers in the German rubber industry: 1981-91. Occup Environ Med 1996;53:289-98.

21 Weiland SK, Straif K, Chambless L, et al. Workplace risk factors for cancer in the German rubber industry: part 1. Mortality from respiratory cancers. Occup Environ Med 1998;55:317-24. 
22 Straif K, Weiland SK, Werner B, et al. Workplace risk factors for cancer in the German rubber industry: part 2. Mortality from non-respiratory cancers. Occup Environ Med 1998;55 325-32.

23 World Health Organisation. International classification of diseases, 9th revision. Geneva: WHO, 1975:1

24 Kromhout H, Heederik D. Occupational epidemiology in the rubber industry: implications of exposure variability. Am f Ind Med 1995;27:171-85.

25 Kromhout H, Swuste P, Boleij JS. Empirical modelling of chemical exposure in the rubber-manufacturing industry. Ann Occup Hyg 1994;38:3-22.

26 British Rubber Manufacturers' Association. Toxicity and safe handling of rubber chemicals. BRMA code of practice, 2 nd ed. Birmingham: BRMA, 1985.

27 International Agency for Research on Cancer. Some aromatic amines, anthraquinones and nitroso compounds, and inorganic fluorides used in drinking-water and dental preparations. Lyon: IARC, 1982

28 Buglass AJ, Challis BC, Osborne MR. Transnitrosation and decomposition of nitrosamines. IARC Sci Publ 1974;9:94100 .

29 Oury B, Limasset JC, Protois JC. Assessment of exposure to carcinogenic $\mathrm{N}$-nitrosamines in the rubber industry. Int Arch Occup Environ Health 1997;70:261-71.

30 Berger MR, Schmähl D. Syncarcinogenesis at low exposure levels of three nitrosamines with a common target of carcinogenic action: preliminary results. IARC Sci Publ 1987;84: $246-9$

31 British Medical Association. TRGS 552 N-Nitrosamine. Bundesarbeitsblatt. London: BMA, 1996:1-2.

32 Checkoway H, Pearce N, Crawford Brown D. Research methods in occupational epidemiology. Oxford: Oxford University Press, 1989.

33 Greenland S, Finkle WD. A critical look at methods for handling missing covariates in epidemiologic regression analyses. Am f Epidemiol 1995;142:1255-64.

34 Kristensen P. Bias from non-differential but dependent misclassification of exposure and outcome. Epidemiology 1992; 3:210-5.

35 Dosemeci M, Wacholder S, Lubin JH. Does non-differential misclassification of exposure always bias a true effect toward the null value? Am f Epidemiol 1990;132:746-8.

36 Wacholder S, Hartge P, Lubin JH, et al. Non-differential misclassification and bias towards the null: a clarification [letter]. Occup Environ Med 1995;52:557-8.

37 Sorahan T, Gilthorpe MS. Non-differential misclasification and bias towards the null: a clarification [letter]. Occup Environ Health 1995;52:558.

38 Rothman KJ, Greenland S. Modern epidemiology, 2nd edition Philadelphia: Lippincott-Raven, 1998.

39 Roman E, Carpenter L. Cancer incidence in England, 1981-7. In: Drever F, ed. Occupational health. Decennial supplement. London: The Stationery Office, 1995:77-102.

40 Delzell E, Louik C, Lewis J, et al. Mortality and cancer morbidity among workers in the rubber tire industry. Am f Ind Med 1981;2:209-16.

41 Solionova LG, Smulevich VB. Mortality and cancer incidence in a cohort of rubber workers in Moscow. Scand f Work Environ Health 1993;19:96-101.

42 Sorahan T, Parkes HG, Veys CA, et al. Mortality in the British rubber industry 1946-85. Br F Ind Med 1989;46:1-10.

43 Straughan JK. Cancer risk in the rubber industry: a review of recent epidemiological evidence [letter]. Occup Environ Med 1998;55:646-7.

44 Huebner WW, Schoenberg JB, Kelsey JL, Wilcox HB, McLaughlin JK, Greenberg RS, et al. Oral and pharyngeal cancer and occupation: a case-control study. Epidemiology cancer and occup

45 Baxter PJ, Werner JB. Mortality in the British rubber industries 1967-76. London: Her Majesty's Stationery Office, 1980.

46 Monson RR, Nakano KK. Mortality among rubber workers. I. White male union employees in Akron, Ohio. Am $\mathcal{F}$ Epidemiol 1976;103:284-96.

47 Rogers MA, Vaughan TL, Davis S, et al. Consumption of nitrate, nitrite, and nitrosodimethylamine and the risk of upper aerodigestive tract cancer. Cancer Epidemiol Biomarkers Prev 1995;4:29-36.

48 Murphy SE, Carmella SG, Idris AM, et al. Uptake and metabolism of carcinogenic levels of tobacco-specific nitrosamines by Sudanese snuff dippers. Cancer Epidemiol Biomarkers Prev 1994;3:423-8.

49 Hoffmann D, Melikian AA, Wynder EL. Scientific challenges in environmental carcinogenesis. Prev Med 1996;25 $14-22$

50 Gupta PC, Murti PR, Bhonsle RB. Epidemiology of cancer by tobacco products and the significance of TSNA. Crit Rev Toxicol 1996;26:183-98.

51 Preston-Martin S. Evaluation of the evidence that tobaccospecific nitrosamines (TSNA) cause cancer in humans. Crit Rev Toxicol 1991;21:295-8.

52 International Agency for Research on Cancer. Some naturally occurring substances: food items and constituents, heterocyclic aromatic amines and mycotoxins. Lyon: IARC, 1993.

53 Zou XN, Lu SH, Liu B. Volatile N-nitrosamines and their precursors in Chinese salted fish: a possible etiological factor for NPC in China. Int $\mathcal{f}$ Cancer 1994;59:155-8.

54 Anderson LM, Souliotis VL, Chhabra SK, et al. $\mathrm{N}$-nitrosodimethylamine-derived $\mathrm{O}(6)$-methylguanine in DNA of monkey gastrointestinal and urogenital organs and enhancement by ethanol. Int f Cancer 1996;66:130-4.

55 Norell S, Ahlbom A, Lipping H, et al. Oesophageal cancer and vulcanisation work. Lancet 1983;i:462-3.
56 Kogevinas M, Sala M, Boffetta P, et al. Cancer risk in the rubber industry: a review of the recent epidemiological evidence. Occup Environ Med 1998;55:1-12.

57 Fan TY, Morrison J, Rounbehler DP, et al. N-Nitrosodiethanolamine in synthetic cutting fluids: a part-per-hundred impurity. Science 1977;196:70-1.

58 Zingmark PA, Rappe C. On the formation of $\mathrm{N}$-nitrosodiethanolamine in a grinding fluid concentrate after storage. Ambio 1977;6:237-8.

59 Spiegelhalder B, Preussmann R, Hartung M. Biological monitoring in the metal working industry. IARC Sci Publ 1984;57:943-6.

60 Fuchs J, Burg J, Hengstler JG, et al. DNA damage in mononuclear blood cells of metal workers exposed to $\mathrm{N}$-nitrosodiethanolamine in synthetic cutting fluids. Mutat Res 1995;342:95-102.

61 Sullivan PA, Eisen EA, Woskie SR, et al. Mortality studies of metalworking fluid exposure in the automobile industry: vi. a case-control study of esophageal cancer. Am F Ind Med 1998;34:36-48.

$62 \mathrm{Lu} \mathrm{SH}$, Chui SX, Yang WX, et al. Relevance of $\mathrm{N}$-nitrosamines to oesophageal cancer in China. IARC Sci Publ 1991;105:11-7.

63 Cheng KK, Day NE, Duffy SW, et al. Pickled vegetables in the aetiology of oesophageal cancer in Hong Kong Chinese. Lancet 1992;339:1314-8.

64 Preussmann R, Stewart BW. N-Nitroso carcinogens. Searle $\mathrm{CE}$, ed. Chemical carcinogens, 2nd ed. Washington, DC: American Chemical Society, 1984:643-828.

65 Druckrey H, Preussmann R, Ivankovic S, et al. Organotropic carcinogenic effects of 65 various $\mathrm{N}$-nitroso-compounds on $\mathrm{BD}$ rats. Zeitschrift für Krebsforschung und Klinische Onkologie 1967;69:103-201

66 Harris CC, Autrup H, Stoner GD, et al. Metabolism of benzo(a)pyrene, N-nitrosodimethylamine, and N-nitrosopyrrolidine and identification of the major carcinogenDNA adducts formed in cultured human esophagus. Cancer Res 1979;39:4401-6.

67 Huang Q, Stoner G, Resau J, et al. Metabolism of $\mathrm{N}$-nitrosomethyl-n-amylamine by microsomes from human and rat esophagus. Cancer Res 1992;52:3547-51.

68 Mirvish SS, Huang Q, Chen SC, et al. Metabolism of carcinogenic nitrosamines in the rat and human esophagus and induction of esophageal adenocarcinoma in rats. Endoscopy 1993;25:627-31.

69 Saffhill R, Badawi AF, Hall CN. Detection of O6methylguanine in human DNA. IARC Sci Publ 1988;89: $301-5$.

70 Umbenhauer D, Wild CP, Montesano R, et al. O(6)Methyldeoxyguanosine in oesophageal DNA among individuals at high risk of oesophageal cancer. Int 7 Cancer 1985;36:661-5.

71 Smith TJ, Liao A, Wang LD, et al. Characterization of xenobiotic-metabolizing enzymes and nitrosamine metaboism in the human esophagus. Carcinogenesis 1998;19:66772.

72 Ross RK, Schottenfeld D. Prostate cancer. Schottenfeld D, Fraumeni JF, eds. Cancer epidemiology and prevention, 2nd ed. Oxford: Oxford University Press, 1996:1180-207.

73 Pour PM. Prostatic cancer induced in MRC rats by N-nitrosobis(2-oxopropyl)-amine and N-nitrosobis(2hydroxypropyl)amine. Carcinogenesis 1983;4:49-55.

74 Pour P, Lawson TA, Cohen SM. Proliferative changes in the prostate. Toxicol Appl Pharmacol 1989;101:499-509.

75 Shirai T, Tamano S, Takahashi S, et al. Animal prostate carcinoma models: limited potential for vertebral metastasis. In: Karr JP, Yamanaka $\mathrm{H}$, eds. Prostate cancer and bone metastasis. New York: Plenum Press, 1992:151-8.

76 Shirai T, Yamamoto A, Imaida K, et al. Lack of synergism among DMAB, BOP, and MNU in induction of carcinomas of the rat ventral prostate. Teratog Carcinog Mutagen 1992;12:71-7.

77 McMichael AJ, Spirtas R, Gamble JF, et al. Mortality among rubber workers: relationship to specific jobs. $\mathcal{7}$ Occup Med 1976;18:178-85.

78 Monson RR, Fine LJ. Cancer mortality and morbidity among rubber workers. I Natl Cancer Inst 1978;61:104753.

79 Goldsmith DF, Smith AH, McMichael AJ. A case-control study of prostate cancer within a cohort of rubber and tire workers. F Occup Med 1980;22:533-41.

80 Tolbert PE, Eisen EA, Pothier LJ, et al. Mortality studies of machining-fluid exposure in the automobile industry. II. Risks associated with specific fluid types. Scand 7 Work Environ Health 1992;18:351-60.

81 Mancuso TF. Occupational cancer survey in Ohio. Proceedings of the Public Health Cancer Association of America. San of the Public Health Cancer Associ

82 Holmberg B, Westerholm P, Maasing R, et al. Retrospective cohort study of two plants in the Swedish rubber industry. Scand $\mathcal{F}$ Work Environ Health 1983;9(suppl 2):59-68.

83 Szeszenia Dabrowska N, Wilczynska U, et al. Cancer mortality among male workers in the Polish rubber industry. Polish fournal of Occupational Medicine 1991;4:149-57.

84 Bernardinelli L, de Marco R, Tinelli C. Cancer mortality in an Italian rubber factory. Br f Ind Med 1987;44:187-91.

85 Norseth T, Andersen A, Giltvedt J. Cancer incidence in the rubber industry in Norway. Scand $\mathcal{F}$ Work Environ Health 983;9(suppl 2):69-71.

86 Englund A, Ekman G, Zabrielski L. Occupational categories among brain tumor cases recorded in the cancer registry in Sweden. Ann N Y Acad Sci 1982;381:188-96. 
87 Bovet P, Lob M. Cancer mortality among the workers of a Swiss rubber goods factory. Epidemiological study, 1955ed Wochenschr 1980;110:1277-87.

88 Lamperth Seiler E. Urinary tract and brain neoplasms in workers of rubber plants. Schweiz Med Wochenschr 1974 104:1655-9.

89 Burch JD, Craib KJ, Choi BC, et al. An exploratory case-control study of brain tumors in adults. $\mathcal{F}$ Natl Cancer Inst 1987;78:601-9.

90 Preston-Martin S, Mack W, Henderson BE. Risk factors for gliomas and meningiomas in males in Los Angeles County. Cancer Res 1989;49:6137-43.

91 Preston-Martin S, Mack W. Gliomas and meningiomas in men in Los Angeles County: investigation of exposures to N-nitroso compounds. IARC Sci Publ 1991;105:197-203.

92 McMichael AJ, Andjelkovic DA, Tyroler HA. Cancer mortality among rubber workers: an epidemiologic study. Ann N Y Acad Sci 1976;271:125-37.

93 Andjelkovich D, Taulbee J, Symons M. Mortality experience of a cohort of rubber workers, 1964-73. F Occup Med of a cohort of rub

94 Negri E, Piolatto G, Pira E, et al. Cancer mortality in a northern Italian cohort of rubber workers. Br f Ind Med northern Italian

95 Symons MJ, Andjelkovich DA, Spirtas R, et al. Brain and central nervous system cancer mortality in US rubber workers. Ann N Y Acad Sci 1982;381:146-59.

96 Preston-Martin S, Yu MC, Benton B, et al. N-Nitroso compounds and childhood brain tumors: a case-control study. Cancer Res 1982;42:5240-5.

97 Chhabra SK, Souliotis VL, Kyrtopoulos SA, et al. Nitrosamines, alcohol, and gastrointestinal tract cancer: recent epidemiology and experimentation. In Vivo 1996; 10:265-84.

98 Magee PN. The experimental basis for the role of nitroso compounds in human cancer. Cancer Surv 1989;8:207-39.

99 Bartsch H. N-nitroso compounds and human cancer: where do we stand? IARC Sci Publ 1991;105:1-10.

100 Preston-Martin S, Correa P. Epidemiological evidence for the role of nitroso compounds in human cancer. Cancer the role of nitroso com
Surv $1989 ; 8: 459-73$.

101 Straif K, Weiland SK, Keil U. Occupational risk factors for gastric cancer: an overview. Am f Epidemiol 1998;147:60810.

102 Wu Y, Chen J, Ohshima H, et al. Geographic association between urinary excretion of $\mathrm{N}$-nitroso compounds and oesophageal cancer mortality in China. Int $\mathcal{F}$ Cancer 1993; 54:713-9.

103 De Stefani E, Deneo Pellegrini H, Carzoglio JC, et al. Dietary nitrosodimethylamine and the risk of lung cancer: a case-control study from Uruguay. Cancer Epidemiol Biomarkers Prev 1996;5:679-82.

104 Schroeder JC, Tolbert PE, Eisen EA, et al. Mortality studies of machining fluid exposure in the automobile industry. IV: A case-control study of lung cancer. Am 7 Ind Med 1997;31:525-33.
105 Zheng W, Blot WJ, Shu XO, et al. Risk factors for oral and Tharyngeal cancer in Shanghai, with emphasis on diet. pharyngeal cancer in Shanghai, with emphasi

106 Blot WJ, McLaughlin JK, Devesa SS, et al. Cancers of the oral cavity and pharynx. Schottenfeld D, Fraumeni JF, eds. Cancer epidemiology and prevention, $2 n d$ ed. Oxford: Oxford University Press, 1996:666-80.

107 Selikoff IJ, Hammond EC. Asbestos-associated disease in United States shipyards. CA Cancer f Clin 1978;28:87-99.

108 Gustavsson P, Evanoff B, Hogstedt C. Increased risk of esophageal cancer among workers exposed to combustion products. Arch Environ Health 1993;48:243-5.

109 Gustavsson P, Jakobsson R, Johansson H, et al. Occupational exposures and squamous cell carcinoma of the oral cavity, pharynx, larynx, and oesophagus: a case-contro study in Sweden. Occup Environ Med 1998;55:393-400.

110 Moulin JJ, Wild P, Mur JM, et al. Risk of lung, larynx, pharynx and buccal cavity cancers among carbon electrode manufacturing workers. Scand F Work Environ Health 1989; 15:30-7.

111 Nutt A. Rubber work and cancer-past, present and perspectives. Scand $\mathcal{F}$ Work Environ Health 1983;9(suppl 2):49-57.

112 Doll R, Peto R, Wheatley K, et al. Mortality in relation to smoking: 40 years' observations on male British doctors. BMF 1994;309:901-11.

113 Doll R, Peto R, Hall E, et al. Mortality in relation to consumption of alcohol: 13 years' observations on male British doctors. BMF 1994;309:911-8.

114 Thun MJ, Peto R, Lopez AD, et al. Alcohol consumption and mortality among middle-aged and elderly US adults. N Engl f Med 1997;337:1705-14.

115 Kjaerheim K, Gaard M, Andersen A. The role of alcohol, tobacco, and dietary factors in upper aerogastric tract cancers: a prospective study of 10900 Norwegian men. Cancer Causes Control 1998;9:99-108.

116 International Agency for Research on Cancer. Tobacco smoking. Lyon: IARC, 1986 .

117 International Agency for Research on Cancer. Alcohol drinking. Lyon: IARC, 1988.

118 Anderson LM, Koseniauskas R, Burak ES, et al. Reduced blood clearance and increased urinary excretion of $\mathrm{N}$-nitrosodimethylamine in patas monkeys exposed to ethanol or isopropyl alcohol. Cancer Res 1992;52:1463-8.

119 Swann PF. Effect of ethanol on nitrosamine metabolism and distribution. Implications for the role of nitrosamines in human cancer and for the influence of alcohol consumption on cancer incidence. IARC Sci Publ 1984;57:501-12.

120 Aze Y, Toyoda K, Furukawa F, et al. Enhancing effect of ethanol on esophageal tumor development in rats by initiation of diethylnitrosamine. Carcinogenesis 1993;14:37-40.

121 Griciute L, Castegnaro M, Bereziat JC. Influence of ethyl alcohol on the carcinogenic activity of N-nitrosodi-npropylamine. IARC Sci Publ 1982;41:643-8. 